\title{
REVIEW
}

\section{Allergic rhinitis-induced nasal congestion: its impact on sleep quality}

\author{
*William Storms ${ }^{\mathrm{a}}$ \\ a Director, The Research Center, The William Storms Allergy Clinic, Colorado Springs, C0 80907, USA
}

Received 9th May 2007; accepted 22nd October 2007

\begin{abstract}
Allergic rhinitis (AR) is an extremely common health problem affecting 20 to 40 million Americans and between 10-25\% of the world's population. Patients with AR suffer from both nasal symptoms (congestion, rhinorrhea, itching, and sneezing) and ocular symptoms (itching, redness, and tearing). The negative impact on sleep quality and quantity, and consequently on various aspects of the patient's life, is an under-recognised and under-treated component of AR morbidity. Nasal congestion, which is one of the most bothersome and prevalent symptoms of $A R$, is thought to be the leading symptom responsible for rhinitis-related sleep problems.

In addition to reducing clinical symptoms, pharmacologic therapies for AR that specifically reduce inflammatory cells and mediators - and therefore nasal congestion and other symptoms - should also improve sleep quality and overall quality of life (QOL). Intranasal corticosteroids (INS) are the current mainstay of therapy for AR. Results of a number of clinical trials demonstrate that INS effectively reduce nasal congestion and ocular symptoms, improve sleep quality, and decrease daytime somnolence. Intranasal corticosteroids have also proved to be effective in reducing symptoms of acute rhinosinusitis and nasal polyposis, both of which also negatively impact on sleep quality. Intranasal corticosteroids are considered safe due to their low systemic bioavailability.

(c) 2008 General Practice Airways Group. All rights reserved.

W Storms. Prim Care Resp J 2008; 17(1): 7-18

doi:10.3132/pcrj.2008.00001
\end{abstract}

Keyw ords allergic rhinitis (AR), intranasal corticosteroids (INS), treatment, congestion, sleep, quality of life (QOL)

\section{Contents}

Introduction

Mechanisms of nasal congestion: impact on sleep quality and sleep-disordered breathing

Clinical evidence of association between nasal congestion and sleep disturbances

Pharmacologic management of allergic rhinitis and associated sleep disturbance

Acute rhinosinusitis and nasal polyposis: association with allergic rhinitis and impact on sleep

Conclusions.

References

\section{Introduction}

Allergic rhinitis (AR) is an extremely common health problem, affecting 20 to 40 million Americans, approximately $26 \%$ of the population in the United Kingdom, and approximately 10 $25 \%$ of the population worldwide. ${ }^{1-6}$ It is characterised by inflammation of the upper airway mucous membranes mediated by binding of antigens to specific immunoglobulin E (IgE) antibodies. The most bothersome symptoms for patients are nasal congestion, runny nose, postnasal drip, red itchy eyes, and headaches, according to a recent survey of 2,500 adults diagnosed with AR. ${ }^{7}$

Another important and perhaps under-appreciated aspect of $A R$ is its negative impact on patients' quality of life (QOL). A total of $80 \%$ of patients in the aforementioned survey complained of being frequently $(44 \%)$ or sometimes (36\%) tired because of their nasal allergy problems, and nearly twothirds reported that they frequently or sometimes felt miserable or irritable during the allergy season. ${ }^{7}$ In another 
survey of 1,322 self-reported AR sufferers, over half indicated that their allergy condition interfered with sleep $(68 \%$ among those with perennial AR and $51 \%$ among those with seasonal AR). ${ }^{8}$

The daytime tiredness experienced by the vast majority of AR sufferers is directly related to the fact that patients with AR experience disrupted sleep at night. ${ }^{9 \cdot 12}$ In addition to daytime fatigue and somnolence, nocturnal sleep impairment is also associated with depression, irritability, memory deficits, inability to concentrate, decreased alertness, and overall reduced QOL. ${ }^{13}$ Consequently, many of the sequelae of $A R$, such as fatigue, decreased cognitive functioning and work performance, and reduced QOL, may be caused or worsened by AR-related sleep impairment. ${ }^{14-17}$ The importance of ARrelated sleep impairment is acknowledged in both the International Primary Care Respiratory Group (IPCRG) guidelines for the management of $A R^{18}$ and in the Allergic Rhinitis and its Impact on Asthma (ARIA) guidelines, ${ }^{2}$ in which the presence of abnormal sleep is one of the factors that reclassifies the severity of $A R$ from mild to moderate/severe. The achievement of unimpaired sleep, therefore, is a primary goal of AR treatment.

Nasal congestion is one of the most bothersome and prevalent symptoms of $A R$ and it occurs in approximately $90 \%$ of patients. ${ }^{19,20}$ In fact, it may be the AR symptom most closely associated with rhinitis-related sleep problems. Other nasal and ocular rhinitis symptoms - such as nasal itching also play a role in awakening patients. ${ }^{21,22}$ In a recent survey of 2,355 individuals with self-reported AR in the United States, nasal congestion affected $80 \%$ or more of respondents in some way at night, causing them to wake up or making it difficult to fall asleep. ${ }^{20}$ The effect of nasal congestion on sleep increased as the severity of congestion intensified. Several lines of clinical evidence also suggest that the nasal obstruction caused by congestion is an important aetiologic factor for sleep-disordered breathing. ${ }^{10-12,23}$

This article summarises the relationship between ARinduced nasal congestion and sleep disturbances, as well as various treatment options for $A R$ and their relative impact on congestion-related sleep problems.

\section{Mechanisms of nasal congestion: impact on sleep quality and sleep-disordered breathing}

The nose is the primary route of breathing during sleep. ${ }^{24,25}$ Studies in normal subjects demonstrate that nasal breathing increases ventilation by stimulating certain receptors in the nasal airway, and that occlusion of the nasal airway may produce decreased oropharyngeal patency. ${ }^{26-28}$ Therefore, the nasal congestion associated with AR can limit maximal upper airway airflow and contribute to sleep disturbances. ${ }^{29}$
Specific types of sleep disturbances or sleep-disordered breathing (SDB) related to increased airway resistance include snoring, upper airway resistance syndrome, and obstructive sleep apnoea syndrome. Snoring is associated with changes in the calibre of the upper airway which reduce flow and increase airway resistance, and is a manifestation of increased turbulence in nasal flow. ${ }^{26}$ Upper airway resistance syndrome is caused by sleep-related flow limitation and increases in upper airway resistance that precipitate arousals - resulting in fragmented sleep and excessive daytime sleepiness. ${ }^{30}$ Obstructive sleep apnoea syndrome is the complete or partial collapse of the upper airway during sleep, with consequent cessation of breathing despite ongoing respiratory effort. Obstructive sleep apnoea syndrome is associated with sleep fragmentation and excessive daytime sleepiness, neuropsychiatric complications (e.g., sleepiness, depression, and cognitive dysfunction), and cardiovascular complications - including pulmonary and systemic hypertension, congestive heart failure, myocardial infarction, and stroke. ${ }^{29,31}$

Allergic rhinitis-associated nasal congestion results from dilation of venous capacitance vessels in the nasal submucosa and increased vascular permeability, mucosal oedema with influx of inflammatory cells, and excess secretions. ${ }^{26}$ The allergic response is composed of two phases: the early phase and late phase. During the early-phase nasal allergic response, antigen deposition on the mucosal surface results in binding of IgE antibodies to respiratory mucosal mast cells and peripheral blood basophils. Consequent mast cell degranulation and release of chemical mediators (e.g., histamine, leukotrienes, and proinflammatory cytokines) is the process primarily responsible for sneezing, itching, and rhinorrhea. ${ }^{32-34}$ Nasal congestion - the predominant late phase symptom - results from the infiltration of inflammatory cells (eosinophils and $\mathrm{T}$ cells) into tissue, and consequent prolonged release of mediators (histamine, leukotrienes, and prostaglandins). ${ }^{25}$

Nasal congestion increases in the supine position, thus worsening its effects during sleep. ${ }^{35}$ In addition, nasal congestion, rhinorrhea, and sneezing exhibit circadian rhythms, with the greatest intensity in early morning, thus exacerbating their negative effects on sleep. ${ }^{36,37}$ Allergic rhinitis-related inflammatory mediators also exhibit a circadian pattern, with levels peaking in early morning. ${ }^{38}$ In addition, sympathetic tone decreases at night, resulting in a relative parasympathetic excess, which is associated with nasal congestion and reduced bronchial dilation. ${ }^{39}$

Several mediators involved in the allergic response also have been implicated in the pathophysiology of sleep disruption. For example, inflammatory cytokines have been associated with suppression of REM and non-REM sleep. To the extent that REM is associated with restorative function, its 
Table 1. Mediators generated in allergic rhinitis and associated with sleep changes.

\begin{tabular}{lll} 
Mediator & Effect on sleep & Effect on nasal airway obstruction \\
\hline Histamine & $\begin{array}{l}\text { Involved in balance between wakefulness and slow-wave activity } \\
\text { during sleep through } \mathrm{H}_{1} \text { receptors in the brain }\end{array}$ & Slight $\uparrow$ \\
CysLT & $\uparrow$ Slow-wave sleep & $\uparrow$ \\
IL-1 & Effects probably mediated in part through $\uparrow$ PGD $; \uparrow$ non-REM sleep; \\
& associated with $\downarrow$ latency to sleep onset; $\uparrow$ latency to REM and $\downarrow$ REM duration & - \\
IL-4 & Associated with $\downarrow$ latency to sleep onset; $\uparrow$ latency to REM and $\downarrow$ REM duration \\
IL-10 & Associated with $\downarrow$ latency to sleep onset; $\uparrow$ latency to REM and $\downarrow$ REM duration & - \\
TNF- $\alpha$ & Probably mediated through $\uparrow$ PGD 2 & $\uparrow$ \\
PGD 2 & $\uparrow$ REM; $\uparrow$ non-REM \\
Bradykinin & & \\
Substance $P$ & $\uparrow$ Latency to REM , arousing effect
\end{tabular}

$\uparrow$, increase; $\downarrow$ decrease; CysLT, cysteinyl leukotriene; IL, interleukin; TNF, tumor necrosis factor; $P G D_{2}$, prostaglandin $D_{2}$; REM, rapid eye movement. None of the above mediators associated with AR have been proved to cause increased sleep in humans.

Reprinted from Otolaryngol Head Neck Surgery, Vol 130, Ferguson, "Influences of allergic rhinitis on sleep," p. 617-629, Copyright 2004, with permission from American Academy of Otolaryngology-Head and Neck Surgery Foundation, Inc.

disruption results in fatigue, reduced concentration, and diminished productivity (see Table 1). ${ }^{39-41}$ Studies have shown that histamine receptors in the brain regulate the sleep-wake cycle and memory, and are involved in maintaining arousal and cognition. .2-44 $^{2-4}$

\section{Clinical evidence of association between nasal congestion and sleep disturbances}

Several observational studies over the last two decades have indicated an association between sleep disturbances (including microarousals, obstructive apnoeas, snoring, and excessive daytime sleepiness) and AR-associated nasal congestion. ${ }^{10-12,45}$ For example, Lavie and colleagues observed increased periodic breathing, hypo- and hyperpneic episodes, and microarousals from sleep, in 14 patients with AR. ${ }^{12}$ The authors hypothesised that increased upper airway resistance and nasal discharge was the cause. These findings were supported by a study that measured nasal resistance and polysomnography in seven patients with seasonal (ragweed) $A R$ both during and following the ragweed season. ${ }^{10}$ Investigators found that the rate of obstructive apnoeas significantly decreased when out of the subjects' allergy season, and that the frequency of obstructive apnoeas was associated with a significant decrease in mean nasal resistance. Similarly, in a study of 39 children with habitual snoring, McColley and colleagues found a high prevalence of allergy (36\%) that was approximately three times the norm for the general pediatric population. ${ }^{45}$

Perhaps the most convincing link between sleep disturbances and AR-associated nasal congestion is the results from a population-based observational study that gathered data on nasal congestion history and sleep problems by questionnaire from 4,927 subjects and by objective laboratory measurements in 911 subjects. ${ }^{11}$ Participants who experienced frequent rhinitis symptoms (at least five nights per month) were significantly more likely to experience habitual snoring, chronic excessive daytime sleepiness, or chronic non-restorative sleep (see Figure 1). Participants reporting nasal congestion due to allergy were 1.8 times more likely to have moderate-to-severe SDB than were those without nasal congestion.

Adding to the evidence of a link between AR-associated nasal congestion and sleep disturbances are the results of several clinical studies demonstrating concomitantly reduced nasal congestion, improved sleep quality, and decreased daytime fatigue/sleepiness after treatment of $A R$ patients with intranasal corticosteroids (INS) (see Table 2, and next section). ${ }^{23,24}$

\section{Pharmacologic management of allergic rhinitis and associated sleep disturbance} Pharmacologic treatment of AR should be guided by the type 
Figure 1. Prevalence of habitual snoring and hypersomnolence by frequency of night-time symptoms of rhinitis $(n=4,927)$. *Self-reported occurrence of night-time nasal congestion or discharge.

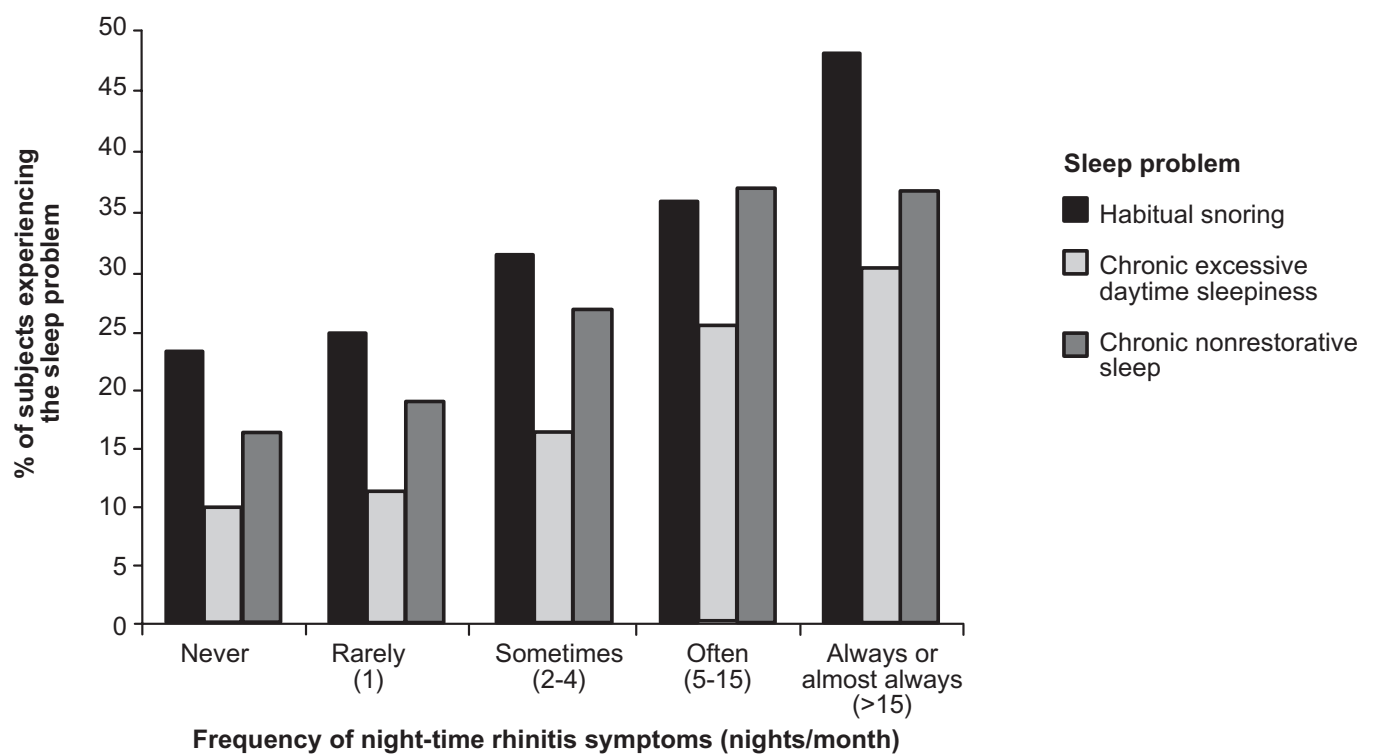

Adapted from J Allergy Clin Immunol, Vol 99, Young, Finn and Kim, "Nasal obstruction as a risk factor for sleep-disordered breathing," p. S757-S762, Copyright 1997, with permission from American Academy of Allergy, Asthma, and Immunology.

and severity of the individual patient's symptoms and, ideally, should reduce nasal congestion, sneezing, and rhinorrhea over the course of the entire day and night.

Antihistamines are a mainstay of therapy for AR and are effective at reducing pruritus, sneezing, and watery rhinorrhea. ${ }^{2}$ They do not, however, significantly reduce nasal obstruction when compared with INS. ${ }^{46}$ Limited data suggest that some second-generation antihistamines, such as cetirizine and fexofenadine, may have favourable effects on sleep in patients with AR, though further study is needed to characterise fully and to confirm these effects. ${ }^{47,48}$ Firstgeneration antihistamines are generally more effective in controlling rhinorrhea compared with second-generation agents, most likely due to their greater anticholinergic effects. However, their use is markedly limited by these anticholinergic effects that can cause dry mouth, tachycardia, and urinary retention, and by their affinity for $\mathrm{H}_{1}$ receptors in the central nervous system (CNS) which results in marked sedation, daytime somnolence, decreased reaction time, and impaired performance. ${ }^{46,49-52}$ The significant sedation associated with first-generation and certain secondgeneration antihistamines is attributed to their high liposolubility and low molecular weight - which allows penetration into the CNS - and their high affinity for CNS histamine $\mathrm{H}_{1}$ receptors. ${ }^{42,49.53}$ M ost newer second-generation antihistamines have minimal or no sedating properties (due to minimal CNS penetration and a low affinity for central $\mathrm{H}_{1}$ receptors) and less anticholinergic effects and are therefore preferable to first-generation antihistamines in most cases. ${ }^{46-49}$ The second-generation antihistamine, cetirizine, however, does penetrate the CNS and occupy central $\mathrm{H}_{1}$ receptors to some extent, resulting in increased sedation compared with fexofenadine. ${ }^{42,53,54}$ Azelastine, an intranasal antihistamine with anti-inflammatory properties, has reduced nasal congestion and improved subjective sleep quality in small studies, but was also found to cause somnolence. ${ }^{55,56}$

Decongestants are sympathomimetic drugs that constrict capacitance vessels in the turbinates and decrease nasal congestion. ${ }^{46}$ Intranasal formulations act quickly, but their utility is limited by congestion rebound (rhinitis medicamentosa) that can occur after just a few days of regular use.46,57,58 However, compared with intranasal formulations such as xylometazoline, oral decongestants such as pseudoephedrine - are only modestly effective at improving nasal flow. ${ }^{59}$ In addition, they have stimulatory properties that can produce insomnia, restlessness, and agitation. ${ }^{60}$

Intranasal corticosteroids are considered first-line therapy for moderate-to-severe seasonal and perennial AR. ${ }^{46}$ They suppress many of the inflammatory mediators implicated in the allergic reaction, and effectively reduce nasal symptoms including congestion, rhinorrhea, sneezing, and pruritus, ${ }^{46,61-65}$ and ocular itching, redness, and tearing. ${ }^{66-68}$ Onset of effect of INS is 6-12 hours, and maximum benefit is achieved after a week or more of regular use. However, as-needed use can also be effective..$^{39,68-69}$ Intranasal corticosteroids are generally 
Table 2. Selected studies evaluating the impact of intranasal corticosteroids on allergic rhinitis-related nasal congestion and associated sleep disturbance.

\begin{tabular}{|c|c|c|c|c|}
\hline Study & Treatment arms & Study Design & Duration & Results* \\
\hline Craig, $2003^{72}$ & $\begin{array}{l}\text { Fluticasone vs placebo } \\
\text { ( } n=32 \text {, crossed over to } \\
\text { both treatments) }\end{array}$ & $\mathrm{DB}, \mathrm{PC}$, crossover & $\begin{array}{l}4 \text { weeks of each } \\
\text { treatment }\end{array}$ & $\begin{array}{l}\text { - Improved subjective sleep }(\mathrm{p}=0.04 \text { ) } \\
\text { - Reduced daytime sleepiness and } \\
\text { fatigue }>10 \% \text { (NS) } \\
\text { - No difference between groups in } \\
\text { apnoea/hypopnoea index }\end{array}$ \\
\hline Craig, $1998^{23}$ & $\begin{array}{l}\text { Flunisolide twice daily vs } \\
\text { placebo ( } n=20 \text { total) }\end{array}$ & $\begin{array}{l}\text { DB, PC, crossover } \\
\text { incorporating } \\
\text { Balaam's design }\end{array}$ & $\begin{array}{l}8 \text { weeks total } \\
\text { (two 4-week } \\
\text { treatment periods) }\end{array}$ & $\begin{array}{l}\text { - Improved nasal congestion }(p=0.0095) \\
\text { - Improved subjective sleep }(p=0.0119) \\
\text { - Trend toward daytime improved sleepiness } \\
(p=0.08)\end{array}$ \\
\hline Gurevich, $2005^{79}$ & $\begin{array}{l}\text { Budesonide vs placebo } \\
\text { ( } n=26 \text { total) }\end{array}$ & $\begin{array}{l}\text { DB, PC, crossover } \\
\text { incorporating } \\
\text { Balaam's design }\end{array}$ & $\begin{array}{l}8 \text { weeks total } \\
\text { (two 3-week } \\
\text { treatment periods with } \\
\text { a 1-week washout) }\end{array}$ & $\begin{array}{l}\text { - Improved subjective nasal congestion } \\
(p=0.04) \\
\text { - Improved daytime sleepiness }(p=0.01) \\
\text { - Between group differences NS for FOSQ, } \\
\text { RQLQ, and ESS, but showed trend } \\
\text { toward improvements in daytime sleepiness, } \\
Q O L \text {, and daily performance with budesonide }\end{array}$ \\
\hline Kiely, $2004^{76}$ & $\begin{array}{l}\text { Fluticasone vs placebo } \\
\text { ( } n=23 \text { total) }\end{array}$ & $\mathrm{R}, \mathrm{DB}, \mathrm{PC}$, crossover & $\begin{array}{l}\text { Two 4-week } \\
\text { treatment periods }\end{array}$ & $\begin{array}{l}\text { - Subjective improvements in nasal congestion } \\
\text { and daytime alertness ( } p=0.02 \text { for both) } \\
\text { - Significantly lower apnoea-hypopnoea } \\
\text { frequency }(A H I) \text { with fluticasone (median } \\
11.9 \text { vs } 20 ; p<0.05) \text {. } \\
\text { - No differences in objective sleep quality } \\
\text { or snoring by overnight sleep study }\end{array}$ \\
\hline M intz, $2004^{74}$ & $\begin{array}{l}\text { Triamcinolone acetonide } \\
(n=651)\end{array}$ & Open label & 3 weeks & $\begin{array}{l}\text { - Improved overall and individual domain } \\
\text { scores for NRQLQ }(p<0.001) \\
\text { - Improved overall and individual domain } \\
\text { scores for PSQI }(p<0.001)\end{array}$ \\
\hline Mansfield, $2004^{78}$ & $\begin{array}{l}\text { Budesonide ( } n=14 \\
\text { children } 4 \text { to } 9 \text { years old) }\end{array}$ & Open label & 6 weeks & $\begin{array}{l}\text { - Reduced mean number of sleep arousals } \\
\text { per hour (baseline of } 8.4 \text { to } 1.2 ; p=0.005 \text { ) } \\
\text { - Improvements on RQLQ consistent } \\
\text { with improved sleep and lessened } \\
\text { rhinitis symptoms }\end{array}$ \\
\hline
\end{tabular}


Table 2. Selected studies evaluating the impact of intranasal corticosteroids on allergic rhinitis-related nasal congestion and associated sleep disturbance continued.

\begin{tabular}{l|l|l|l|l} 
Study & Treatment arms & Study Design & Duration & Results* \\
\hline Ratner, 200375 & $\begin{array}{l}\text { Fluticasone } 200 \mu \mathrm{g} \\
\text { daily }(\mathrm{n}=353) \mathrm{vs} \\
\text { montelukast } 10 \mathrm{mg} \text { daily } \\
(\mathrm{n}=352)\end{array}$ & R, DB, parallel group & 15 days & $\begin{array}{l}\text { Statistically significant differences favouring } \\
\text { fluticasone over montelukast for mean } \\
\text { change from baseline in: } \\
\text { - Daytime total }(p<0.001) \text { and individual } \\
\text { nasal symptom scores }(p<0.001) \\
\text { - Night-time total }(p<0.001) \text { and individual } \\
\text { nasal symptom } 5 c 0 \text { ses }(p \leq 0.002)\end{array}$ \\
\hline
\end{tabular}

*Expressed as efficacy/superiority of active treatment vs placebo except where otherwise noted.

DB, double blind; ESS, Epworth Sleepiness Scale; FOSQ, Functional Outcome of Sleep Questionnaire; NRQLQ, Nocturnal Rhinoconjunctivitis Quality of Life Questionnaire; NS, not statistically significant; PC, placebo controlled; PSQI, Pittsburgh Sleep Quality Index; QOL, quality of life; R, randomised; RQLQ, Rhinoconjunctivitis Quality of Life Questionnaire.

considered safe in adults and children due to their topical administration and low systemic bioavailability. ${ }^{70}$

Intranasal corticosteroids appear to be one of the most effective agents for controlling nasal obstruction secondary to AR. Therefore, given the significant impact of AR-associated nasal congestion on sleep quality, the efficacy of INS in relieving nasal congestion suggests that these agents would reduce sleep problems and associated daytime somnolence. Indeed, this has been demonstrated in several clinical studies, based both on subjective daily diary data and on several validated instruments assessing sleep quality, sleep-related QOL, and nocturnal rhinitis-related QOL (see Table 2). ${ }^{23,24,71-80}$

Two small similarly-designed placebo-controlled crossover trials in patients with perennial AR demonstrated significant trends toward improvements in nasal congestion, subjective sleep, and daytime somnolence (as recorded in daily diaries) with INS (flunisolide in one study and budesonide in the other) vs placebo (Figure 2).23,24 The INS fluticasone has also significantly improved subjective sleep quality vs placebo $(p=0.04)$ in 32 patients with perennial AR and chronic sleep problems. $^{72}$ In this double-blind, randomised, 8-week crossover study, daytime somnolence, daytime fatigue, all categories of the sleep-related QOL Questionnaire (QLQ, rhinoconjunctivitis specific), and the Epworth sleepiness scale (ESS) also improved, but not to a statistically significant extent. Lack of correlation between polysomnography changes and QOL (except at visit 3) may be explained by nonadherence to therapy - a common reason why patients who are prescribed a topical agent fail to maintain response. ${ }^{72}$ In a much larger open-label study of more than 500 patients with AR, intranasal triamcinolone acetonide was associated with significant improvements in nocturnal QOL - assessed with the Nocturnal Rhinoconjunctivitis QOL questionnaire (NRQLQ) - and in sleep quality - assessed with the Pittsburgh Sleep
Quality Index (PSQI).74

As would be expected, based on their mechanism of action and demonstrated benefit in improving sleep in AR patients, INS significantly reduce most night-time nasal symptoms of $A R$, as demonstrated by the effect of mometasone furoate nasal spray (MFNS) in a large doubleblind, placebo-controlled, parallel-group trial of 245 patients with seasonal AR. ${ }^{73}$ Once-daily treatment with MFNS produced significant improvement in night-time symptoms of congestion, nasal itching, and sneezing (Figure 3a) and in all individual daytime symptoms (cough, rhinorrhea, congestion, nasal itching, and sneezing) (Figure 3b). The baseline mean night-time total nasal symptom score was higher for the M FNS group compared with the placebo group (9.3 vs 8.8; $p=0.04)$. Children with $A R$ have also benefited from reduced sleep arousals (from a baseline of 8.4 to 1.2 per hour $[p=0.005])$ and improved sleep and rhinitis symptoms with INS, based on results of an open trial with intranasal budesonide. ${ }^{78}$

Other pharmacologic options for the management of $A R$ include leukotriene receptor antagonists, mast cell stabilisers, and immunotherapy. Leukotriene receptor antagonists (e.g., montelukast) block the effects of cysteinyl leukotrienes, which are important mediators of early- and late-phase allergic response, including nasal congestion. ${ }^{80-83}$ Montelukast significantly improved daytime symptoms (congestion, rhinorrhea, pruritus, sneezing) and night-time symptoms (difficulty going to sleep, night-time awakenings, and congestion on awakening) in several studies of patients with seasonal AR. ${ }^{84.86}$ Further study is needed to confirm the benefit of montelukast therapy on sleep. Mast cell stabilisers such as intranasal cromolyn sodium inhibit the degranulation of sensitised mast cells, reducing the release of mediators that trigger inflammation and the allergic response..$^{25}$ Cromolyn 
Figure 2. Effect of intranasal corticosteroid on sleep quality and nasal congestion in 22 patients with perennial allergic rhinitis. Severity of symptoms decreases in the budesonide group compared with placebo with respect to daytime sleepiness $(p=0.02)$, daytime fatigue $(p=0.03)$, sleep problems $(p=0.05)$, and nasal congestion $(p=0.08)$. Scale: 0 (none) to 4 (severe).

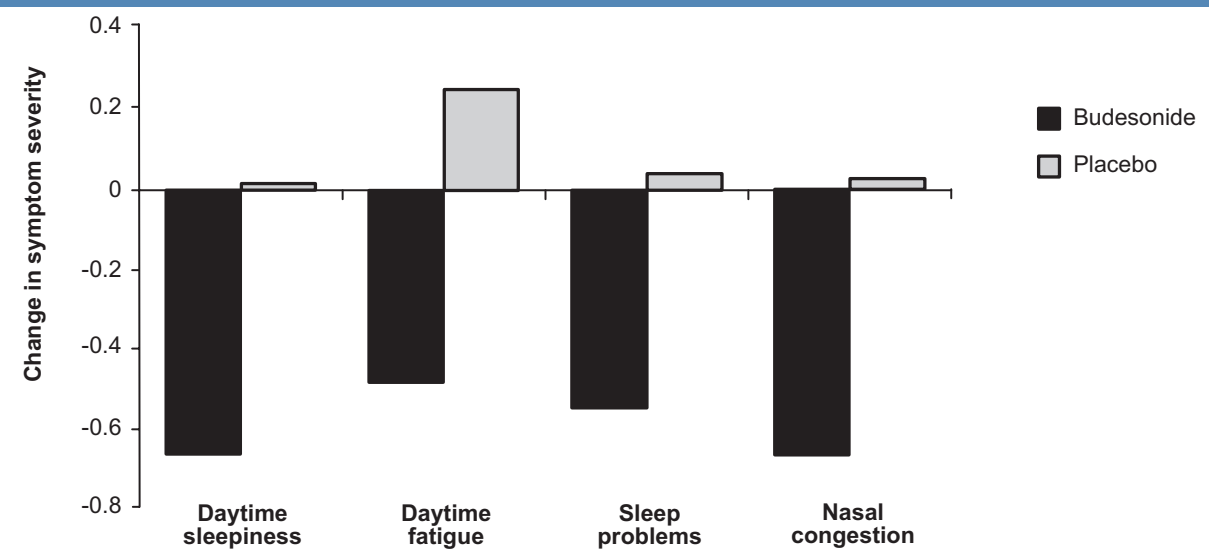

Reprinted from Allergy, Vol 58, Hughes, Glass, Ripchinski, Gurevich, Weaver, Lehman, Fisher, and Craig, "Efficacy of the topical nasal steroid budesonide on improving sleep and daytime somnolence in patients with perennial allergic rhinitis," p. 380-385, Copyright 2003, with permission from Blackwell Publishing.

Figure 3(a). Relief of individual night-time nasal symptoms and cough at endpoint with intranasal mometasone furoate in 245 patients with seasonal allergic rhinitis. Figure 3(b). Relief of individual daytime nasal symptoms and cough at endpoint with intranasal mometasone furoate.

a.

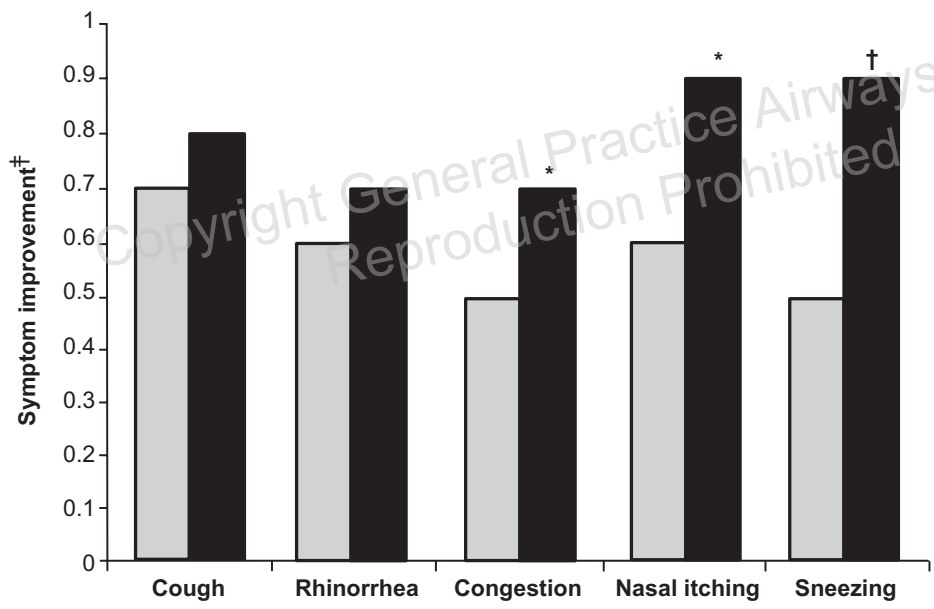

MFNS $200 \mu \mathrm{g}$ qd

$\square$ Placebo

* $p<0.05$ vs placebo

$\dagger \mathrm{p}<0.01$ vs placebo

† Mean reduction from baseline

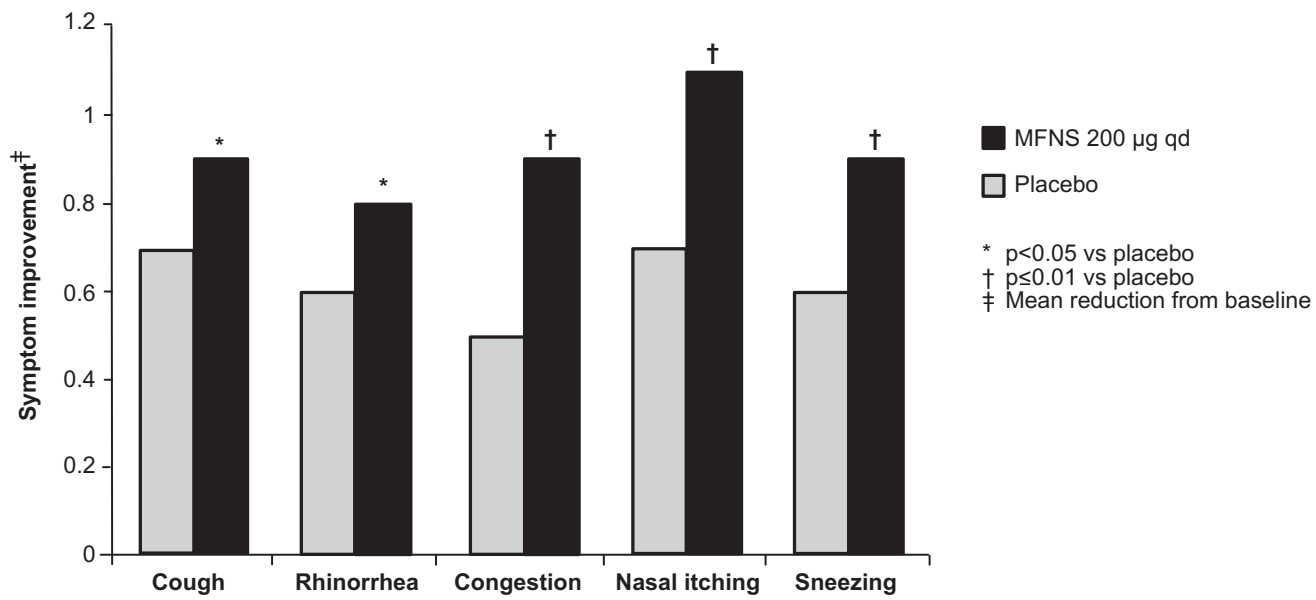

Reprinted from Annals of Allergy, Asthma, \& Immunology, Vol 90, Gawchik, Goldstein, Prenner, and John, "Relief of cough and nasal symptoms associated with allergic rhinitis by mometasone furoate nasal spray," p. 416-421, Copyright 2003, with permission from American College of Allergy, Asthma, \& Immunology. 
sodium is a weak anti-inflammatory agent, however, that requires dosing four times daily, is less effective than nasal corticosteroids, and is unlikely to have an effect on nasal congestion. ${ }^{50}$ Its most appropriate use is as a preventive therapy rather than treatment. ${ }^{50}$

Allergen-specific immunotherapy involves administration of gradually increasing quantities of an allergen extract to an allergic patient in order to ameliorate the symptoms associated with subsequent exposure to the causative allergen. It is indicated for patients with evidence of IgEmediated disease and serious or prolonged AR not sufficiently responsive to pharmacotherapy and avoidance measures. Very limited data suggest improved night-time symptoms with immunotherapy in AR patients, but further study is needed. ${ }^{87}$

The vast majority $(72 \%)$ of patients fail to take allergy medicines as prescribed, according to a recent survey of 2,500 adults diagnosed with $A R^{7}{ }^{7}$ The most common reasons cited by patients included perceived lack of symptom relief $(41 \%)$, loss of effectiveness over time (37\%), and lack of symptoms $(35 \%)$. Other reasons included side effects or worry about side effects, cost, and concern about long-term use. These results indicate that a large percentage of the population with allergies do not achieve optimal care and, therefore, stop using their medication. The results also highlight the need to educate patients regarding their medication, including the importance of compliance with medications that are optimally effective with daily use - such as INS - and the expected time frame for onset of response, which should be relatively rapid for an antihistamine or nasal decongestant but may be somewhat slower for INS, particularly in more severe AR. ${ }^{2}$

\section{Acute rhinosinusitis and nasal polyposis: association with allergic rhinitis and impact on sleep}

Besides having a direct negative impact on sleep because of ARassociated nasal congestion, allergic rhinitis may also be a predisposing factor for the development of two other conditions that may have significant negative effects on sleep quality - nasal polyposis and rhinosinusitis - although the majority of nasal polyps are seen in patients with non-allergic rhinitis. ${ }^{288-91}$ Like allergic rhinitis, both nasal polyposis (specifically, inflammatory eosinophilic polyposis) and rhinosinusitis are characterised by degranulation of mast cells and influx of eosinophils, cytokines/chemokines, and their mediators. ${ }^{2,88,92}$ Both of these associations, however, require further investigation. ${ }^{2,91993}$

Nasal polyps are growths that develop in the nasal and sinus membranes and extend into the nasal cavity, causing obstruction and interference with breathing. Nasal polyposis also impairs sense of smell ${ }^{2,94}$ and has been found to impact negatively on QOL and sleep. ${ }^{95}$ Intranasal corticosteroids are effective in treating nasal polyposis, possibly by down- regulating the expression and production of cytokines such as IL-5, which effectively reduces the number of eosinophils. ${ }^{92}$ Intranasal corticosteroids attenuate rhinitis symptoms, improve nasal breathing, and reduce polyp size. Intranasal corticosteroids may partially prevent recurrence of polyps, thus potentially reducing or delaying the need for treatment. 92,96

Intranasal surgery traditionally has been the most common approach to treatment of nasal polyps. However, evidencebased guidelines published in a recent European Academy of Allergology and Clinical Immunology (EAACI) position paper recommend the use of INS as first-line treatment for nasal polyposis. ${ }^{93}$ The EAACl's detailed schematic approach to diagnosis and management highlights $\mathrm{QOL}$ issues with respect to polyposis and recommends use of INS sprays for patients with mild conditions and INS drops for patients with disease of moderate severity. Surgical approaches, such as polypectomy and functional endoscopic sinus surgery are considered for severe cases, but even then INS are recommended as postoperative adjunctive therapy. ${ }^{93}$

To date, however, there have been only a few published studies focusing on INS treatment outcomes in nasal polyposis. Small short-term studies from the 1990 s examined the use of aqueous and powder forms of budesonide ${ }^{97-99}$ and found it to be efficacious in the treatment of small- to largesized polyps. Other studies in patients with severe or bilateral polyposis found evidence of similar efficacy and tolerability of fluticasone propionate or beclomethasone dipropionate, with some evidence that fluticasone had a more rapid onset of action. ${ }^{100-102}$ However, these reports lack the kinds of sizable effects that can be translated into practical application in a clinical setting. ${ }^{103}$ The largest of these studies included fewer than 150 patients, with most enrolling fewer than 100 individuals, and the longest study was of only six months' duration. Moreover, none of these study drugs was found to have an effect on olfactory impairment. The EAACI position paper has highlighted the need for a long-term follow-up study of a cohort of patients with polyposis as a priority area for future research. ${ }^{93}$

Mometasone furoate is an INS indicated for treatment of nasal polyposis in the United States. ${ }^{104}$ In 354 subjects with bilateral nasal polyps and significant congestion/obstruction, mometasone furoate $200 \mu \mathrm{g}$ given once or twice daily over 4 months significantly reduced bilateral nasal polyp grade score ( $p<0.001$ and $p=0.010$, respectively) and congestion/ obstruction ( $p=0.001$ and $p<0.001$, respectively) compared with placebo. The twice daily regimen was more effective in reducing congestion/obstruction. Significant improvements were also seen in the secondary endpoints of anterior rhinorrhea, postnasal drip, and loss of smell. ${ }^{96}$ These results were confirmed in a similarly designed 4-month trial in 310 
patients with bilateral nasal polyps. ${ }^{105}$ In that trial, mometasone furoate $200 \mu \mathrm{g}$ once or twice daily produced greater reductions in polyp grade at endpoint compared with placebo, with differences reaching statistical significance for twice daily dosing $(p=0.04)$. Both regimens achieved statistically superior improvements from baseline in congestion and/or obstruction score vs placebo by the end of the first month.

Budesonide is another INS that has been studied for the management of nasal polyps, although it is not currently approved for this indication. ${ }^{102-107}$ In 183 patients with moderate-sized nasal polyps causing clinically significant symptoms, budesonide aqueous nasal spray at a dose of 128 $\mu \mathrm{g}$ once or twice daily, or $256 \mu \mathrm{g}$ once daily for eight weeks significantly reduced polyp size $(p<0.01)$ and improved peak nasal inspiratory flow $(p<0.001)$ compared with placebo. ${ }^{106}$ Combined and individual symptom scores (blocked nose, runny nose, and sneezing) and sense of smell also improved significantly in all budesonide-treated groups. These findings were confirmed by results of a similarly designed 8-week trial comparing budesonide $140 \mu \mathrm{g}$ once or twice daily, $280 \mu \mathrm{g}$ once daily, or placebo in 157 patients with symptomatic bilateral nasal polyposis. ${ }^{107}$ Polyp size was significantly reduced by the $280 \mu \mathrm{g}$ once daily dose and the $140 \mu \mathrm{g}$ twice daily dose, and all three budesonide doses significantly reduced symptom scores. ${ }^{107}$

In addition to their role in the treatment of nasal polyposis specifically, INS may play a major role in the management of acute and chronic rhinosinusitis with or without nasal polyps, according to the EAACl guidelines. ${ }^{93}$ Acute rhinosinusitis is an upper respiratory tract disorder primarily caused by viral inflammation of the nasal and sinus mucosal membrane that is often followed by a bacterial infection. Symptoms include congestion, purulent discharge, and postnasal drip, as well as headache and facial pressure. ${ }^{91,108}$ Interestingly, sleep disturbance, fatigue, nasal blockage, and nasal discharge were more reliable predictors of a rhinosinusitis diagnosis (confirmed by computed tomography scan) than were headache or facial pain or pressure. ${ }^{109}$ Most patients with symptoms of acute rhinosinusitis are treated with antibiotics; however, the viral nature of most rhinosinusitis infections suggest that antibiotics may be overused. ${ }^{110,111}$

Patients with chronic rhinosinusitis, and chronic rhinosinusitis with nasal polyposis, commonly present with nasal obstruction, nasal discharge, facial pressure, pain, and hyposmia of prolonged duration. ${ }^{112}$ Recent evidence suggests that chronic rhinosinusitis and chronic rhinosinusitis with nasal polyposis are distinct entities with separate inflammatory pathways and cytokine profiles. ${ }^{112}$ Antibiotics and INS are the mainstay of treatment for chronic rhinosinusitis, while primary treatment for chronic sinusitis with nasal polyposis consists of combination systemic and INS. ${ }^{112}$ The efficacy of INS in these conditions is thought to be secondary to the re-establishment of sinus ostia patency. ${ }^{112}$

Intranasal corticosteroids, either as adjuncts to antibiotics, or as monotherapy, have shown positive effects on acute rhinosinusitis symptoms in several large, placebo-controlled trials. Two small-scale studies in pediatric patients with acute sinusitis found that budesonide may be useful as ancillary treatment to antibiotics and was effective for the reduction of such sleep-disruptive symptoms as headache, stuffiness, cough, and nasal discharge. ${ }^{113,114}$ Studies in patients with maxillary, recurrent, or acute sinusitis have found that use of flunisolide or mometasone as adjunctive treatment is well tolerated and significantly more effective for the reduction of symptoms than antibiotic therapy alone. ${ }^{115-117}$ A University of Michigan Health System Guideline for Clinical Care has cited high-dose INS spray formulations as likely to be effective in acute and chronic rhinosinusitis, but has indicated that more research is required. ${ }^{118}$

Only limited clinical evidence is currently available to support the role of INS as monotherapy for acute rhinosinusitis. In a double-blind trial of 981 patients with acute rhinosinusitis, mean morning/evening major symptom score was significantly improved with mometasone furoate $200 \mu \mathrm{g}$ monotherapy twice daily for 15 days compared with amoxicillin monotherapy for 10 days $(p=0.002)$ or placebo $(p<0.001){ }^{108}$ Patients receiving mometasone furoate were more satisfied with symptom relief compared with patients in the amoxicillin or placebo groups, and there was no indication of recurrence of rhinosinusitis or susceptibility for bacterial infection after INS therapy was discontinued. ${ }^{108}$ The greatest symptom improvement was for night waking, an important finding given the prevalence of sleep impairment in this population. ${ }^{110}$ The EAACl has cited a need for future research comparing INS monotherapy with antibiotics in patients with intermittent or persistent rhinosinusitis. ${ }^{93}$

\section{Conclusions}

The deleterious impact of AR-associated sleep impairment on various aspects of the patient's life is an important component of AR morbidity that may be under-recognised and under-treated by healthcare providers. ${ }^{119}$ Nasal congestion, which is one of the most bothersome and prevalent symptoms of $A R$, is thought to be the leading symptom responsible for rhinitis-related sleep problems. Pharmacologic management of AR should strive to improve daytime and night-time symptoms. Therapies that specifically reduce inflammatory cells and mediators, and produce relief of clinical symptoms, should also improve sleep quality and result in improved overall QOL. ${ }^{39}$ Intranasal corticosteroids are a current mainstay of therapy for AR. Results of a number of 
clinical trials demonstrate that INS effectively reduce the nasal and ocular symptoms associated with $A R$, especially congestion, improve sleep quality, and decrease daytime somnolence. Intranasal corticosteroids have also proved to be effective in reducing symptoms of acute rhinosinusitis and nasal polyposis, both of which also negatively impact on sleep quality. Intranasal corticosteroids are considered safe due to their low systemic bioavailability.

\section{Conflict of interest}

William Storms has conducted research studies for Alcon, Altana, AstraZeneca, BMS, Genentech, GSK, Medpointe, Merck, Novartis, Sanofi-Aventis, and Schering. He is/has been a board member or has acted as a consultant for the following companies: Adams, Alcon, Altana, AstraZeneca, Consumer Reports/Consumers Union, Efficas, Exaeris, Genentech, Greer, GSK, Hoffman-La Roche, Inspire, Isis, Ivax, King, Medpointe, Merck, Nexcura, Novartis, Sanofi-Aventis, Schering, Sepracor, Strategic Biosciences, Strategic Pharmaceutical Advisors, TREAT Foundation, Wyeth. He is/has been on the Speakers Bureau of the following companies: Abbott, Alcon, AstraZeneca, Genentech, Medpointe, Merck, Novartis, Pfizer, Sanofi-Aventis, and Schering.

\section{References}

1. Skoner DP. Allergic rhinitis: definition, epidemiology, pathophysiology, detection, and diagnosis. J Allergy Clin Immunol 2001;108:2-8.

2. Bousquet J, van Cauwenberge $\mathrm{P}$, Khaltaev N; Aria Workshop Group; World Health Organization. Allergic rhinitis and its impact on asthma. J Allergy Clin Immunol 2001;108:147-336.

3. International Consensus Report on the diagnosis and management of rhinitis. International Rhinitis M anagement Working Group. Allergy 1994;49:1-34.

4. Sibbald B. Epidemiology of allergic rhinitis. In: Burr ML, ed. Epidemiology of clinical allergy. Monographs in Allergy Basel:Karger;1993. p.61-79.

5. Wuthrich B, Schindler C, Leuenberger P, Ackermann-Liebrich U. Prevalence of atopy and pollinosis in the adult population of Switzerland (SAPALDIA study). Int Arch Allergy Immunol 1995;106:149-56.

6. Bauchau V, Durham SR. Prevalence and rate of diagnosis of allergic rhinitis in Europe. Eur Respir J 2004;24:758-64.

7. Allergies in America: A landmark survey of nasal allergy sufferers: Executive Summary. Available for URL: http://www.myallergiesinamerica.com/

8. Blaiss $M$, Reigel T, Philpot E. A study to determine the impact of rhinitis on sufferers' sleep and daily routine [abstract]. J Allergy Clin Immunol 1999:115:197:787.

9. Leger D, Annesi-Maesano I, Carat F et al. Allergic rhinitis and its consequences on quality of sleep. Arch Intern Med 2006;166:1744-8.

10. McNicholas WT, Tarlo S, Cole P et al. Obstructive apneas during sleep in patients with seasonal allergic rhinitis. Am Rev Respir Dis 1982;126:625-8.

11. Young T, Finn L, Kim H. Nasal obstruction as a risk factor for sleep-disordered breathing. The University of Wisconsin Sleep and Respiratory Research Group. J Allergy Clin Immunol 1997;99:S757-62.

12. Lavie P, Gertner R, Zomer J, Podoshin L. Breathing disorders in sleep associated with "microarousals" in patients with allergic rhinitis. Acta Otolaryngol 1981;92:529-33.

13. Flemons WW, Tsai W. Quality of life consequences of sleep-disordered breathing. J Allergy Clin Immunol 1997;99:S750-6.

14. Blaiss MS. Quality of life in allergic rhinitis. Ann Allergy Asthma Immunol 1999:83:449-54

15. Wilken JA, Berkowitz R, Kane R. Decrements in vigilance and cognitive functioning associated with ragweed-induced allergic rhinitis. Ann Allergy Asthma Immunol 2002;89:372-80.

16. Marshall PS, O'Hara C, Steinberg P. Effects of seasonal allergic rhinitis on selected cognitive abilities. Ann Allergy Asthma Immunol 2000;84:403-10.

17. Kessler RC, Almeida DM, Berglund P, Stang P. Pollen and mold exposure impairs the work performance of employees with allergic rhinitis. Ann Allergy Asthma Immunol 2001;87:289-95.

18. Price D, Bond C, Bouchard J et al. International Primary Care Respiratory Group (IPCRG) guidelines: management of allergic rhinitis. Prim Care Resp J 2006;15:58-70. doi:10.1016/j.pcrj.2005.11.002

19. Juniper EF, Guyatt GH, Dolovich J. Assessment of quality of life in adolescents with allergic rhinoconjunctivitis: development and testing of a questionnaire for clinical trials. J Allergy Clin Immunol 1994;93:413-23.

20. Shedden A. Impact of nasal congestion on quality of life and work productivity in allergic rhinitis. Findings from a large online survey. Treat Respir Med 2005;4:439-46.

21. Juniper EF, Rohrbaugh T, M eltzer EO. A questionnaire to measure quality of life in adults with nocturnal allergic rhinoconjunctivitis. J Allergy Clin Immuno 2003:111:484-90.

22. Juniper EF, Thompson AK, Ferrie PJ, Roberts JN. Development and validation of the Mini Rhinoconjunctivitis Quality of Life Questionnaire. Clin Exp Allergy 2000;30:132-40

23. Craig TJ, Teets S, Lehman EB, Chinchilli VM, Zwillich C. Nasal congestion secondary to allergic rhinitis as a cause of sleep disturbance and daytime fatigue and the response to topical nasal corticosteroids. J Allergy Clin Immuno 1998;101:633-7

24. Hughes K, Glass C, Ripchinski M et al. Efficacy of the topical nasal steroid budesonide on improving sleep and daytime somnolence in patients with perennial allergic rhinitis. Allergy 2003;58:380-5.

25. Storms WW. Pharmacologic approaches to daytime and nighttime symptoms of allergic rhinitis. J Allergy Clin Immunol 2004;114:S146-53.

26. Rappai M, Collop N, Kemp S, deShazo R. The nose and sleep-disordered breathing. Chest 2003;124:2309-23.

27. Zwillich CW, Pickett C, Hanson FN, Weil JV. Disturbed sleep and prolonged apnea during nasal obstruction in normal men. Am Rev Respir Dis 1981;124:158-60.

28. Olsen KD, Kern EB, Westbrook PR. Sleep and breathing disturbance secondary to nasal obstruction. Otolaryngol Head Neck Surg 1981;89:804-10.

29. Staevska MT, Mandajieva MA, Dimitrov VD. Rhinitis and sleep apnea. Curr Allergy Asthma Reports 2004;4:193-9.

30. Guilleminault C, Stoohs R, Clerk A, Simmons J, Labanowski M. From obstructive sleep apnea syndrome to upper airway resistance syndrome: consistency of daytime sleepiness. Sleep 1992;15:513-16.

31. Sher AE. An overview of sleep disordered breathing for the otolaryngologist. Ear Nose Throat J 1999;78:a694-5.

32. Hansen I, Klimek L, Mösges R, Hormann K. Mediators of inflammation in the early and the late phase of allergic rhinitis. Curr Opin Allergy Clin Immuno 2004;4:159-63.

33. Gelfand EW. Inflammatory mediators in allergic rhinitis. J Allergy Clin Immunol 2004:114:S135-8

34. Baraniuk JN. Pathogenesis of allergic rhinitis. J Allergy Clin Immunol 1997;99:S763-72

35. Rundcrantz $\mathrm{H}$. Postural variations of nasal patency. Acta Otolaryngol 1969:68:435-43.

36. Smolensky $\mathrm{MH}$, Reinberg $\mathrm{A}$, Labrecque G. Twenty-four hour pattern in symptom intensity of viral and allergic rhinitis: treatment implications. J Allergy Clin Immunol 1995;95:1084-96.

37. Reinberg A, Gervais $P$, Levi $F$ et al. Circadian and circannual rhythms of allergic rhinitis: an epidemiologic study involving chronobiologic methods. J Allergy Clin Immunol 1988;81:51-62.

38. Aoyagi $M$, Watanabe $H$, Sekine $K$ et al. Circadian variation in nasal reactivity in children with allergic rhinitis: Correlation with the activity of eosinophils and basophilic cells. Int Arch Allergy Immunol 1999;120:95-9. 
39. Ferguson BJ. Influences of allergic rhinitis on sleep. Otolaryngol Head Neck Surg 2004;130:617-29.

40. Krouse HJ, Davis JE, Krouse JH. Immune mediators in allergic rhinitis and sleep. Otolaryngol Head Neck Surg 2002;126:607-13.

41. Mullington JM, Hinze-Selch D, Pollmacher T. Mediators of inflammation and their interaction with sleep: relevance for chronic fatigue syndrome and related conditions. Ann NY Acad Sci 2001;933:201-10.

42. Tashiro M, Mochizuki $\mathrm{H}$, Iwabuchi $\mathrm{K}$ et al. Roles of histamine in regulation of arousal and cognition: functional neuroimaging of histamine $\mathrm{H} 1$ receptors in human brain. Life Sci 2002;72:409-14.

43. Onodera K, Miyazaki S, Imaizumi M et al. Improvement by FUB 181, a novel histamine H3-receptor antagonist, of learning and memory in the elevated plusmaze test in mice. Naunyn-Schmiedeberg Arch Pharmacol 1998;357:508-13.

44. Parmentier R, Ohtsu H, Djebbara-Hannas et al. Anatomical, physiological, and pharmacological characteristics of histidine decarboxylase knock-out mice: evidence for the role of brain histamine in behavioral and sleep-wake control. J Neurosci 2002;22:7695-711.

45. McColley SA, Carroll JL, Curtis S, Loughlin GM, Sampson HA. High prevalence of allergic sensitization in children with habitual snoring and obstructive sleep apnea. Chest 1997;111:170-3.

46. van Cauwenberge P, Bachert C, Passalacqua G et al. Consensus statement on the treatment of allergic rhinitis. European Academy of Allergology and Clinical Immunology. Allergy 2000;55:116-34.

47. Murray JJ, Nathan RA, Bronsky EA, Olufade AO, Chapman D, Kramer B. Comprehensive evaluation of cetirizine in the management of seasonal allergic rhinitis: impact on symptoms, quality of life, productivity, and activity impairment. Allergy Asthma Proc 2002;23:391-8.

48. M eltzer EO, Casale TB, Nathan RA et al. Once-daily fexofenadine $\mathrm{HCl}$ improves quality of life and reduces work and activity impairment in patients with seasonal allergic rhinitis. Ann Allergy Asthma Immunol 1999;83:311-17.

49. Camelo-Nunes IC. New antihistamines: a critical review.J Pediatr (Rio J) 2006;82:173-80

50. Kakumanu S, Glass C, Craig T. Poor sleep and daytime somnolence in allergic rhinitis: significance of nasal congestion. Am J Respir Med 2002;1:195-200.

51. Vuurman EFPM, van Veggel LM A, Uiterwijk M MC et al. Seasonal allergic rhinitis and antihistamine effects on children's learning. Ann Allergy 1993;71:121-6.

52. Weiler JM, Bloomfield JR, Woodworth GG et al. Effects of fexofenadine, diphenhydramine, and alcohol on driving performance: a randomized, placebo-controlled trial in the lowa driving simulator. Ann Intern Med 2000;132:354-63.

53. Tashiro $M$, Sakurada $Y$, Iwabuchi $K$ et al. Central effects of fexofenadine and cetirizine: measurement of psychomotor performance, subjective sleepiness, and brain histamine $\mathrm{H1}$-receptor occupancy using 11C-doxepin positron emission tomography. J Clin Pharmacol 2004;44:890-900.

54. Cetirizine hydrochloride [package insert]. New York, NY: Pfizer Inc; 2007.

55. Saengpanich $S$, Assanasen $P$, de Tineo $M$ et al. Effects of intranasal azelastine on the response to nasal allergen challenge. Laryngoscope 2002;112:47-52.

56. Golden S, Teets SJ, Lehman EB et al. Effect of topical nasal azelastine on the symptoms of rhinitis, sleep, and daytime somnolence in perennial allergic rhinitis. Ann Allergy Asthma Immunol 2000;85:53-7.

57. Ramey JT, Bailen E, Lockey RF. Rhinitis medicamentosa. J Investig Allergol Clin Immunol 2006;16:148-55.

58. Dykewicz MS, Fineman S, Skoner DP et al. Diagnosis and management of rhinitis: complete guidelines of the Joint Task Force on Practice Parameters in Allergy, Asthma, and Immunology. Ann Allergy Asthma Immunol 1998;81:478518.

59. Caenen M, Hamels K, Deron P, Clement P. Comparison of decongestive capacity of xylometazoline and pseudoephedrine with rhinomanometry and MRI. Rhinology 2005;43:205-09.

60. Moinuddin $\mathrm{R}$, deTineo $\mathrm{M}$, Maleckar $\mathrm{B}$ et al. Comparison of the combinations of fexofenadine-pseudoephedrine and loratadine-montelukast in the treatment of seasonal allergic rhinitis. Ann Allergy Asthma Immunol 2004;92:73-9.

61. Fokkens WJ, Godthelp T, Holm AF et al. Allergic rhinitis and inflammation: the effect of nasal corticosteroid therapy. Allergy 1997;52:29-32.

62. Juliusson S, Holmberg $\mathrm{K}$, Karlsson $\mathrm{G}$ et al. Mast cells and mediators in the nasal mucosa after allergen challenge. Effects of four weeks' treatment with topical glucocorticoid. Clin Exp Allergy 1993;23:591-9.

63. Rak S, Jacobson MR, Sudderick RM et al. Influence of prolonged treatment with topical corticosteroid (fluticasone propionate) on early and late phase nasal responses and cellular infiltration in the nasal mucosa after allergen challenge. Clin Exp Allergy 1994;24:930-9.

64. Davies RJ, Nelson HS. Once-daily mometasone furoate nasal spray: efficacy and safety of a new intranasal glucocorticoid for allergic rhinitis. Clin Ther 1997; 19:27-38

65. Meltzer EO, Orgel HA, Bronsky EA et al. A dose-ranging study of fluticasone propionate aqueous nasal spray for seasonal allergic rhinitis assessed by symptoms, rhinomanometry, and nasal cytology. J Allergy Clin Immuno 1990;86:221-30.

66. DeWester J, Philpot EE, Westlund RE et al. The efficacy of intranasal fluticasone propionate in the relief of ocular symptoms associated with seasonal allergic rhinitis. Allergy Asthma Proc 2003;24:331-7.

67. Schenkel E, LaForce C, Gates D. M ometasone furoate nasal spray in seasonal allergic rhinitis. Allergy Clin Immunol Int 2007;19:50-3

68. Kaiser HB. Naclerio RM, Given J et al. Fluticasone furoate nasal spray: a single treatment option for the symptoms of seasonal allergic rhinitis. J Allergy Clin Immunol 2007;119:1430-7.

69. Jen $A$, Baroody $F$, de Tineo $M$ et al. As-needed use of fluticasone propionate nasal spray reduces symptoms of seasonal allergic rhinitis. J Allergy Clin Immunol 2000;105:732-8.

70. Wilson AM, Sims EJ, M CFarlane LC et al. Effects of intranasal corticosteroids on adrenal, bone, and blood markers of systemic activity in allergic rhinitis. J Allergy Clin Immunol 1998;102:598-604.

71. Craig TJ, Hanks CD, Fisher LH. How do topical nasal corticosteroids improve sleep and daytime somnolence in allergic rhinitis? J Allergy Clin Immuno 2005;116:1264-6

72. Craig TJ, M ende C, Hughes K, Kakumanu S, Lehman EB, Chinchilli V. The effect of topical nasal fluticasone on objective sleep testing and the symptoms of rhinitis, sleep, and daytime somnolence in perennial allergic rhinitis. Allergy Asthma Proc 2003;24:53-8.

73. Gawchik S, Goldstein S, Prenner B, John A. Relief of cough and nasal symptoms associated with allergic rhinitis by mometasone furoate nasal spray. Ann Allergy Asthma Immunol 2003;90:416-21.

74. Mintz M, Garcia J, Diener P, Liao Y, Dupclay L, Georges G. Triamcinolone acetonide aqueous nasal spray improves nocturnal rhinitis-related quality of life in patients treated in a primary care setting: the Quality of Sleep in Allergic Rhinitis study. Ann Allergy Asthma Immunol 2004;92:255-61.

75. Ratner PH, Howland WC III, Arastu R et al. Fluticasone propionate aqueous nasal spray provided significantly greater improvement in daytime and nighttime nasal symptoms of seasonal allergic rhinitis compared with montelukast. Ann Allergy Asthma Immunol 2003;90:536-42.

76. Kiely JL, Nolan P, McNicholas WT. Intranasal corticosteroid therapy for obstructive sleep apnoea in patients with co-existing rhinitis. Thorax 2004; $59: 50-5$

77. Berger WE, Nayak AS, Staudinger HW. Mometasone furoate improves congestion in patients with moderate-to-severe seasonal allergic rhinitis. Ann Pharmacother 2005;39:1984-9.

78. Mansfield LE, Diaz G, Posey CR, Flores-Neder J. Sleep disordered breathing and daytime quality of life in children with allergic rhinitis during treatment with intranasal budesonide. Ann Allergy Asthma Immunol 2004;92:240-4. 
79. Gurevich F, Glass C, Davies M et al. The effect of intranasal steroid budesonide on the congestion-related sleep disturbance and daytime somnolence in patients with perennial allergic rhinitis. Allergy Asthma Proc 2005;26:268-74.

80. Bisgaard H, Olsson P, Bende M. Effect of leukotriene D4 on nasal mucosal blood flow, nasal airway resistance and nasal secretions in humans. Clin Allergy 1986;16:289-97.

81. Okuda M, Watase T, Mezawa A, Liu CM. The role of leukotriene D4 in allergic rhinitis. Ann Allergy 1988;60:537-40.

82. White M. Mediators of inflammation and the inflammatory process. J Allergy Clin Immunol 1999;103:S378-81.

83. Naclerio R. Clinical manifestations of the release of histamine and other inflammatory mediators. J Allergy Clin Immunol 1999;103:S382-5.

84. Philip G, Malmstrom K, Hampel FC et al. Montelukast for treating seasonal allergic rhinitis: a randomized, double-blind, placebo-controlled trial performed in the spring. Clin Exp Allergy 2002;32:1020-8.

85. van Adelsberg J, Philip G, LaForce CF et al. Randomized controlled trial evaluating the clinical benefit of montelukast for treating spring seasonal allergic rhinitis. Ann Allergy Asthma Immunol 2003;90:214-22.

86. Nayak AS, Philip G, Lu S et al. Efficacy and tolerability of montelukast alone or in combination with loratadine in seasonal allergic rhinitis: a multicenter, randomized, double-blind, placebo-controlled trial performed in the fall. Ann Allergy Asthma Immunol 2002a;88:592-600.

87. Can D, Tanac R, Demir E, Gulen F, Veral A. Efficacy of pollen immunotherapy in seasonal allergic rhinitis. Pediatrics International 2007;49:64-69.

88. Kirtsreesakul V, Naclerio RM. Role of allergy in rhinosinusitis. Curr Opin Allergy Clin Immunol 2004;4:17-23.

89. Slavin RG. Sinusitis in adults and its relation to allergic rhinitis, asthma, and nasal polyps. J Allergy Clin Immunol 1988;82:950-6.

90. Berrettini S, Carabelli A, Sellari-Franceschini S et al. Perennial allergic rhinitis and chronic sinusitis: correlation with rhinologic risk factors. Allergy 1999;54:242-8.

91. Hellings PW, Fokkens WJ. Allergic rhinitis and its impact on otorhinolaryngology. Allergy 2006;61:656-64

92. Mygind N, Dahl R, Bachert C. Nasal polyposis, eosinophil dominated inflammation, and allergy. Thorax 2000;55:79-83.

93. Fokkens $\mathrm{W}$, Lund $\mathrm{V}$, Bachert $\mathrm{C}$ et al. EAACI position paper on rhinosinusitis and nasal polyps executive summary. Allergy 2005;60:583-601.

94. Bachert C, Hörmann K, Mösges R et al. An update on the diagnosis and treatment of sinusitis and nasal polyposis. Allergy 2003;58:176-91.

95. Serrano E, Neukirch F, Pribil C et al. Nasal polyposis in France: impact on sleep and quality of life. J Laryngol Otol 2005;119:543-9.

96. Small CB, Hernandez J, Reyes A et al. Efficacy and safety of mometasone furoate nasal spray in nasal polyposis. J Allergy Clin Immunol 2005;116:127581.

97. Vendelbo Johansen L, Illum P, Kristensen S, Winther L, Vang Petersen S, Synnerstad B. The effect of budesonide (Rhinocort ${ }^{\circledR}$ ) in the treatment of smal and medium-sized nasal polyps. Clin Otolaryngol 1993;18:524-7.

98. Lildholdt T, Rundcrantz H, Lindqvist N. Efficacy of topical corticosteroid powder for nasal polyps: a double-blind, placebo-controlled study of budesonide. Clin Otolaryngol Allied Sci 1995;20:26-30.

99. Tos M, Svendstrup $F$, Arndal $H$ et al. Efficacy of an aqueous and a powder formulation of nasal budesonide compared in patients with nasal polyps. Am J Rhinol 1998;12:183-9.

100. Holmberg K, Juliusson S, Balder B, Smith DL, Richards DH, Karlsson G. Fluticasone propionate aqueous nasal spray in the treatment of nasal polyposis. Ann Allergy Asthma Immunol 1997;78:270-6.
101. Lund VJ, Flood J, Sykes AP, Richards DH. Effect of fluticasone in severe polyposis. Arch Otolaryngol Head Neck Surg 1998;124:513-18.

102. Penttilä M, Poulsen P, Hollingworth K, Holmström M. Dose-related efficacy and tolerability of fluticasone propionate nasal drops $400 \mu \mathrm{g}$ once daily and twice daily in the treatment of bilateral nasal polyposis: a placebo-controlled randomized study in adult patients. Clin Exp Allergy 2000;30:94-102.

103. Blaiss MS. Expanding the evidence base for the medical treatment of nasal polyposis. J Allergy Clin Immunol 2005;116:1272-4.

104. Nasonex [package insert]. Kenilworth, N]: Schering Corporation; 2005.

105. Stjarne P, Mosges R, Jorissen $M$ et al. A randomized controlled trial of mometasone furoate nasal spray for the treatment of nasal polyposis. Arch Otolaryngol Head Neck Surg 2006;132:179-85.

106.Jankowski R, Schrewelius C, Bonfils $P$ et al. Efficacy and tolerability of budesonide aqueous nasal spray treatment in patients with nasal polyps. Arch Otolaryngol Head Neck Surg 2001;127:447-52.

107. Filaci F, Passali D, Puxeddu R, Schrewelius C. A randomized controlled trial showing efficacy of once daily intranasal budesonide in nasal polyposis. Rhinology 2000;38:185-90.

108. Meltzer EO, Bachert C, Staudinger $\mathrm{H}$. Treating acute rhinosinusitis: comparing efficacy and safety of mometasone furoate nasal spray, amoxicillin, and placebo. J Allergy Clin Immunol 2005;116:1289-95.

109. Kenny TJ, Duncavage J, Bracikowski J et al. Prospective analysis of sinus symptoms and correlation with paranasal computed tomography scan Otolaryngol Head Neck Surg 2001;125:40-3.

110.Small CB, Bachert C, Lund VJ, Moscatello A, Nayak AS, Berger WE. Judicious antibiotic use and intransal corticosteroids in acute rhinosinusitis. Am J Med 2007;120:289-94

111. Sande MA, Gwaltney JM. Acute community-acquired bacterial sinusitis: continuing challenges and current management. Clin Infect Dis 2004;39:1518.

112. Gillespie MB, Osguthorpe JD. Pharmacologic management of chronic rhinosinusitis, alone or with nasal polyposis. Curr Allergy Asthma Rep 2004; 4:478-85

113. Barlan IB, Erkan E, Bakir M, Berrak S, Basaran M M. Intranasal budesonide spray as an adjunct to oral antibiotic therapy for acute sinusitis in children. Ann Allergy Asthma Immunol 1997;78:598-601.

114. Yilmaz G, Varan B, Yilmaz T, Gurakan B. Intranasal budesonide spray as an adjunct to oral antibiotic therapy for acute sinusitis in children. Eur Arch Otorhinolaryngol 2000;257:256-9.

115. Meltzer EO, Orgel HA, Backhaus JW et al. Intranasal flunisolide spray as an adjunct to oral antibiotic therapy for sinusitis. J Allergy Clin Immunol 1993; 92:812-23.

116. M eltzer EO, Charous BL, Busse WW, Zinreich SJ, Lorber RR, Danzig M R. Added relief in the treatment of acute recurrent sinusitis with adjunctive mometasone furoate nasal spray. The Nasonex Sinusitis Group. J Allergy Clin Immuno 2000;106:630-7.

117. Nayak AS, Settipane GA, Pedinoff A et al; Nasonex Sinusitis Group. Effective dose range of mometasone furoate nasal spray in the treatment of acute rhinosinusitis. Ann Allergy Asthma Immunol 2002b;89:271-8.

118. University of Michigan Health System Guidelines for Clinical Care: Acute Rhinosinusitis in Adults. Available for URL: http://cme.med.umich.edu/pdf/ guideline/rhino05.pdf

119. Santanello NC, DeM uro-M ercon C, Shah SR et al. Validation of the nighttime symptoms score as a clinically relevant measure of allergic rhinitis. Allergy Asthma Proc 2006;27:231-9.

\section{Available online at http://www.thepcrj.org}

